\title{
PENENTUAN JALUR EVAKUASI BENCANA GEMPA DAN TSUNAMI DI KOTA WAISAI
}

\author{
Wahyu Adi Putra Mouko \\ 20157011046 \\ Program Studi Teknik Sipil Universitas Muhammadiyah Sorong \\ Jalan Pendidikan No 27 Kota Sorong, Propinsi Papua Barat \\ Email : phutrawahyumouko@gmail.com
}

\begin{abstract}
ABSTRAK
Kabupaten Raja Ampat merupakan hasil pemekaran dari Kabupaten Sorong dan termasuk salah satu dari 14 kabupaten baru di Tanah Papua. Saat ini, Kabupaten Raja Ampat merupakan bagian dari Provinsi Papua Barat yang terdiri dari 4 pulau besar yaitu Pulau Waigeo, Batanta, Salawati dan Misool, dan 1.847 pulau-pulau. Kabupaten Raja Ampat didominasi oleh tiga jalur besar gempa bumi, yakni: Zona konvergensi lempeng Pasifik dan Pulau Papua New Guinea yang kompleks, jalur Sesar Sorong, dan Jalur Sesar Aiduna Tarairua. Dengan kecepatan gerak relatif lempeng Pasifik yang sekitar 120 mm/tahun, maka bisa diterka bahwa wilayah ini mempunyai potensi bencana gempa sekitar dua-kali lipat lebih besar dibandingkan wilayah Sumatra-Jawa yang pergerakan lempengnya hanya 50-70 mm/tahun. Gempa dan Tsunami tidak bisa saling dipisahkan meskipun terjadinya tsunami tidak selalu diakibatkan oleh gempa bumi tapi dalam gempa yang berkekuatan yang tinggi bisa mengakibatkan bencana tsunami. Sumber pembangkitnya diketahui bahwa 90\% dari tsunami tersebut disebabkan oleh aktivitas gempa bumi tektonik, 9\% akibat aktivitas vulkanik dan 1\% oleh tanah longsor yang terjadi dalam tubuh air (danau atau laut) maupun longsoran dari darat yang masuk ke dalam tubuh air. Berdasarkan sumber terjadinya gempa bumi tektonik sangat berpotensi terjadinya tsunami.
\end{abstract}

Kata Kunci : jalur evakuasi; kota waisai ; bencana gempa dan tsunami 
PENDAHULUAN

\section{Latar Belakang}

Kabupetan Raja Ampat merupakan hasil pemekaran dari Kabupaten Sorong dan termasuk salah satu dari 14 kabupaten baru di Tanah Papua. Saat ini, Kabupaten Raja Ampat merupakan bagian dari Provinsi Papua Barat yang terdiri dari 4 pulau besar yaitu Pulau Waigeo, Batanta, Salawati dan Misool, dan 1.847 pulau-pulau kecil, letak geografis Raja Ampat yang berada sebelah selatan laut seram, Sebelah Timur Distrik Sorong Barat Kota Sorong dan Laut Seram di sebelah utara samudra Pasifik, Dan didominasi oleh tiga jalur besar gempa bumi, yakni: Zona konvergensi lempeng Pasifik dan Pulau Papua New Guinea yang kompleks, jalur Sesar Sorong, dan Jalur Sesar Aiduna Tarairua. Dengan kecepatan gerak relatif lempeng Pasifik yang sekitar $120 \mathrm{~mm} /$ tahun, maka bisa diterka bahwa wilayah ini mempunyai potensi bencana gempa sekitar dua-kali lipat lebih besar dibandingkan wilayah Sumatra-Jawa yang pergerakan lempengnya hanya $50-70 \mathrm{~mm} / \mathrm{tahun}$.

Faktanya, sudah sangat sering gempa-gempa besar terjadi di masa lalu, misalnya gempa tsunami di Biak (Mw8.3) yang mengakibatkan tsunami hingga 7 meter $(23 \mathrm{ft})$ memakan korban ribuan jiwa dan gempa yang tiga kali terjadi di wilayah Nabire tahun 2004 dengan kekuatan Mw7.1 sampai Mw7.6.Adapun Gempa bumi Sorong 2015 adalah gempa bumi berkekuatan 6,8 SR yang berpusat di laut berjarak 31 kilometer Timur Laut Kota Sorong, Papua Barat pada 24 September 2015 pada pukul 22.53 WIT dengan kedalaman gempa bumi 10 kilometer. Guncangan gempa ini juga dirasakan di wilayah sekitarnya seperti Kabupaten Raja Ampat, gempa tersebut diarasakan kuat selama 15 detik. Masyarakat berhamburan keluar rumah. Pasien di rumah sakit dievakuasi ke luar gedung. Memang sekarang ini populasi penduduk di wilayah Raja Ampat terutama ibukota waisai masih sedikit demikian juga infrastrukturnya masih belum seperti kota besar sehingga walaupun hazard-nya paling tinggi di wilayah Indonesia tapi risk-nya masih tidak terlalu tinggi, Namun perlu di ingat bahwa faktor resiko bencana ini akan terus naik sejalan dengan laju populasi dan pembangunan, yang kalau tidak mengindahkan faktor bencana akan terus mengisi daerah-daerah yang rawan bencana.

Gempa dan Tsunami tidak bisa saling dipisahkan meskipun terjadinya tsunami tidak selalu diakibatkan oleh gempa bumi tapi dalam gempa yang berkekuatan yang tinggi bisa mengakibatkan bencana tsunami. Sumber pembangkitnya diketahui bahwa 90\% dari tsunami tersebut disebabkan oleh aktivitas gempa bumi tektonik, 9\% akibat aktivitas vulkanik dan $1 \%$ oleh tanah longsor yang terjadi dalam tubuh air (danau atau laut) maupun longsoran dari darat yang masuk ke dalam tubuh air. Berdasarkan sumber terjadinya gempa bumi tektonik sangat berpotensi terjadinya tsunami

\section{Tujuan Penelitian}

Penelitian ini bertujuan untuk merencanakan penentuan jalur evakuasi bencana gempa dan tsunami di kota waisai

\section{STATE OF THE ART}

Adapun penelitian terdahulu yang terkait dengan penelitian ini adalah sebagai berikut :

1. Menurut Ummu Kulsum, M.A Zainul Fuad, \& Andik Isdianto (2017) menyebutkan bahwa Tindakan mitigasi bencana tsunami memerlukan suatu informasi yang berkaitan dengan daerah mana saja yang rawan terkena tsunami. Informasi tersebut dapat diperoleh dari hasil pegolahan data citra satelit dan aplikasi Sistem Informasi Geografis (SIG).

2. Menurut Dini Purbani, Ardiansyah, Lestari Cendikia Dewi1, Joko Prihantono1 \& Rikha Bramawanto (2013) menyebutkan hasil penelitiannya adalah Wilayah yang rentan umumnya terletak di wilayah pesisir, oleh karena itu perlu ditentukan wilayah mana saja yang dapat dijadikan sebagai usulan Tempat Evakuasi Sementara (TES). Melalui pendekatan SIG, penelitian ini mengusulkan agar TES didirikan di wilayah permukiman rawan tsunami yang memiliki fasilitas jalan atau aksesibilitas yang baik. Metode Network Analysis digunakan untuk menentukan permukiman-permukiman yang terjangkau oleh TES yang telah ada (existing) dan menentukan permukiman yang belum terjangkau TES manapun

3. Menurut Andi Syukri, Mukhlis (2016) menyebutjan bahwa Jalur evakuasi horizotal tsunami sebagai salah satu solusi untuk menghadapi masa tanggap darurat setelah terjadinya gempa bumi di laut yang berpotensi menghasilkan gelombang tinggi perlu adanya dilakukan studi komprehensif, Ketersediaan jalan yang memadai untuk memfasilitasi evakuasi terhadap gelombang tsunami sangat bergantung kepada moda transportasi yang digunakan dan kapasitas jalan yang digunakan untuk tempat yang 
lebih tinggi dan juga melihat adanya ketersediaan bangunan tinggi yang layak dijadikan potensi evakuasi secara vertikal.

\section{METODE}

\section{Tahapan Penelitian}

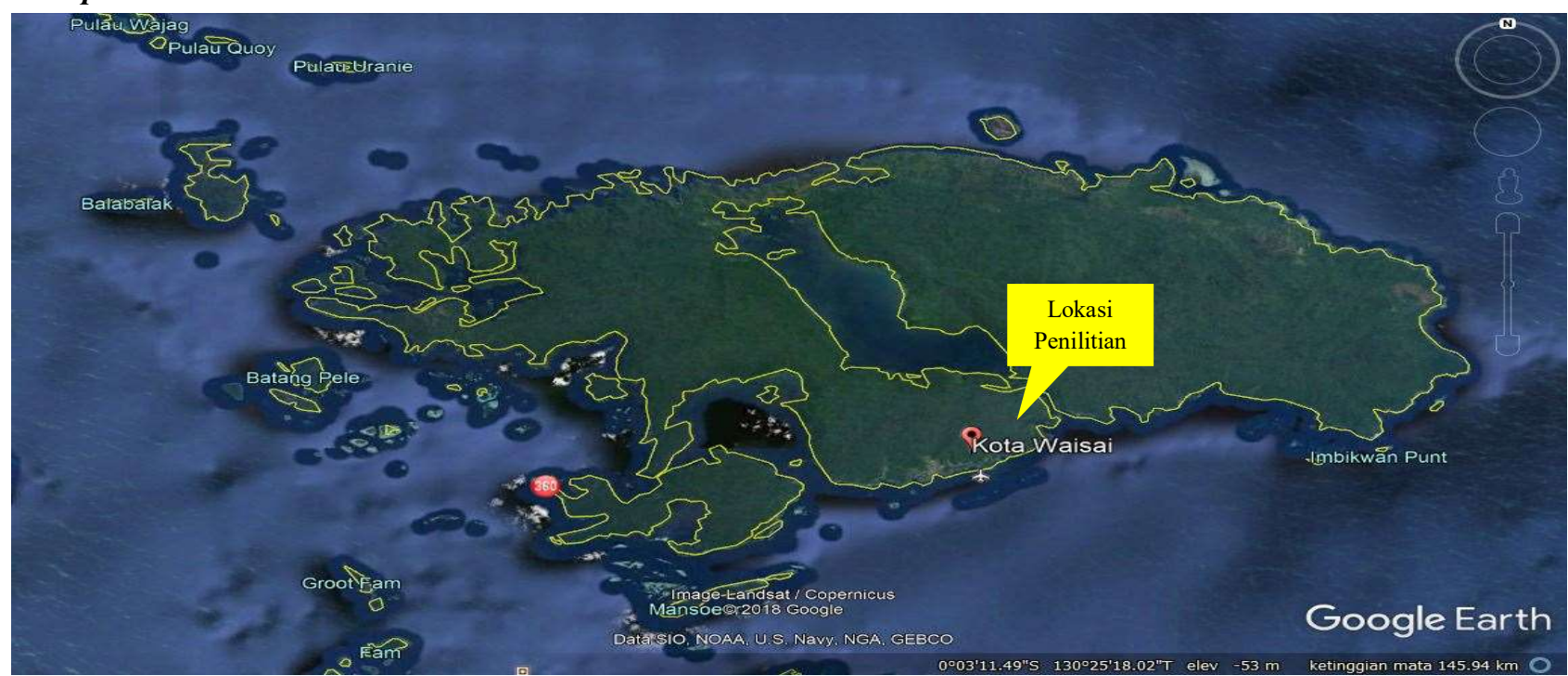

Tahapan penelitian yang digunakan adalah sebagai berikut :

1. Melakukan pengamatan langsung Ke Kota Waisai Kabupaten Raja Ampat

2. Mengolah data dari hasil yang telah di dapatkan pada saat melakukan pengamatan langsung .

3. Mengidentifikasi dan menganalisa untuk pembuatan peta bencana tsunami dan pembuatan peta jalur evakuasi bencana

Semua metode penulisan dan analisa dalam artikel ilmiah ini merujuk pada panduan penulisan tugas akhir Fakultas Teknik Universitas Muhammadiyah Sorong tahun 2014 (Pristianto, Amri, \& Rusdi, 2014). 


\section{REFERENSI}

1. Andi Syukri, Mukhlis. (2016) Studi Jalur Evakuasi Tsunami Horizontal Di Kabupaten Padang Pariaman. Teknik Sipil Politeknik Negeri Padang

2. Bambang Marwanta (2005) Tsunami Di Indonesia Dan Upaya Mitigasinya" Evaluasi Jalur Evakuasi Pada. Universitas Widyatama. Bandung

3. BMKG. (2012). Pedoman Pelayanan Peringatan Dini Tsunami InaTEWS - Edisi Kedua. Kedeputian Bidang Geofisika Badan Meteorologi Klimatologi dan Geofisika, Jakarta.

4. BNPB dan JICA. (2015). Petunjuk Teknis Penyusunan Peta Ancaman Dan Resiko Bencana Untuk Kabupaten/Kota- Edisi Kedua.

5. Dini Purbani, Ardiansyah, dan Lestari Cendikia (2014). Penentuan Tempat Evakuasi Sementara (Tes) Dan Tempat Evakuasi Akhir (Tea) Untuk Gempa Bumi Dan Tsunami Dengan Pendekatan Sistem Informasi Geografis, Kota Pariaman Propinsi Sumatera Barat. Jurusan Geografi FMIPA, Universitas Indonesia

6. BNPB. (2012). Referensi Potensi Kejadian dan Genangan Tsunami Indonesia Peraturan Kepala Badan Nasional Penanggulangan (PERKA BNPB ) - (2008) Pedoman Penyusunan Rencana Penanggulangan Bencana

7. Peraturan Kepala Badan Nasional Penanggulangan (PERKA BNPB ) nomor 02 tahun 2012 Pedoman Umum Pengkajian Resiko BencanaPristianto, $\mathrm{H}$.

8. Ummu Kultsum, M. A Zainul Fuad, dan Andik Isdianto. (2017). Desain Jalur

Evakuasi Tsunami di Daerah Pelabuhan Ratu Kabupaten Sukabumi Menggunakan Sistem Informasi Geografis. Teknik Sipil, Universitas Brawijaya

9. Saruksuk, Johannes Hanzen (2006) Konsep Jaringan Jalan Pada Kota Yang Rawan Bencana Gempa Dan Tsunami. Teknik Sipil Universitas Dipenogoro. Semarang

10. Siklus Bencana https://detafebrianti.wordpress.com/2015/05/20/siklus-penanggulangan- bencana. 